WORKSHOP ON EDUCATIONAL INNOVATION

IN ARCHITECTURE JIDA'17

JORNADES SOBRE INNOVACIÓ

DOCENT EN ARQUITECTURA JIDA'17

ESCUELA TÉCNICA SUPERIOR DE ARQUITECTURA DE SEVILLA 16 Y 17 DE NOVIEMBRE DE 2017 


\section{GILDA}

Organiza e impulsa GILDA (Grupo para la Innovación y Logística Docente en la Arquitectura), en el marco del proyecto RIMA (Investigación e Innovación en Metodologías de Aprendizaje), de la Universitat Politècnica de Catalunya - BarcelonaTech (UPC) y el Institut de Ciències de l'Educació (ICE). https://www.upc.edu/rima/ca/grups/gilda

\section{Editores}

Daniel García-Escudero, Berta Bardí i Milà

\section{Revisión de textos}

Rodrigo Carbajal Ballell, Silvana Rodrigues de Oliveira, Jordi Franquesa

\section{Edita}

Iniciativa Digital Politècnica Oficina de Publicacions Acadèmiques Digitals de la UPC

ISBN 978-84-9880-681-6 (UPC)

elSSN 2462-571X

D.L. B 9090-2014

(C) de los textos y las imágenes: los autores

(C) de la presente edición: Iniciativa Digital Politècnica Oficina de Publicacions Acadèmiques Digitals de la UPC 


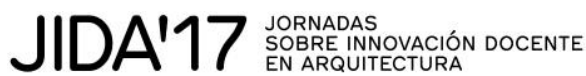

\section{Comité Organizador JIDA'17}

Dirección, coordinación y edición

\section{Berta Bardí i Milà (GILDA)}

Dra. Arquitecta, Departamento de Proyectos Arquitectónicos, ETSAV-UPC

Daniel García-Escudero (GILDA)

Dr. Arquitecto, Departamento de Proyectos Arquitectónicos, ETSAB-UPC

\section{Organización}

Rodrigo Carbajal Ballell (humAP)

Dr. Arquitecto, Departamento de Proyectos Arquitectónicos, ETSA-US

Jordi Franquesa (Coordinador GILDA)

Dr. Arquitecto, Departamento de Urbanismo y Ordenación del Territorio, ETSAB-UPC

Joan Moreno Sanz (GILDA)

Dr. Arquitecto, Departamento de Urbanismo y Ordenación del Territorio, ETSAV-UPC

Silvana Rodrigues de Oliveira (humAP)

Arquitecta, Departamento de Proyectos Arquitectónicos, ETSA-US

Judit Taberna (GILDA)

Arquitecta, Departamento de Representación Arquitectónica, ETSAB-UPC

\section{Comité Científico JIDA'17}

\section{Rodrigo Almonacid Canseco}

Dr. Arq., Dpt. de Teoría de la Arquitectura y Proyectos Arquitectónicos, ETSA Valladolid

Fernando Álvarez Prozorovich

Departamento de Historia y Comunicación, ETSAB-UPC

\section{Atxu Amann Alcocer}

Dra. Arquitecta, Departamento de Proyectos Arquitectónicos, ETSAM-UPM

\section{Silvia Blanco}

Dra. Arquitecta, Centro Superior de Estudios de Galicia, Universidad San Jorge 


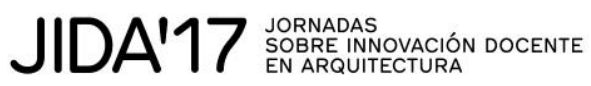

\section{Ivan Cabrera i Fausto}

Dr. Arq., Dpt. de Mecánica de los Medios Continuos y Teoría de Estructuras, ETSA-UPV

\section{Raúl Castellanos Gómez}

Dr. Arquitecto, Departamento de Proyectos Arquitectónicos, ETSA-UPV

\section{Nuria Castilla Cabanes}

Dra. Arquitecta, Departamento de Construcciones arquitectónicas, ETSA-UPV

\section{Eduardo Delgado Orusco}

Dr. Arquitecto, Departamento de Proyectos Arquitectónicos de la Universidad de Zaragoza

\section{Mariona Genís Vinyals}

Dra. Arquitecta, BAU Centro Universitario del Diseño de Barcelona

\section{María González}

Arquitecta, Departamento de Proyectos Arquitectónicos, ETSA-US

\section{Antonio Juárez Chicote}

Dr. Arquitecto, Departamento de Proyectos Arquitectónicos, ETSAM-UPM

\section{Juanjo López de la Cruz}

Arquitecto, Departamento de Proyectos Arquitectónicos, ETSA-US

\section{Nieves Mestre}

Dra. Arquitecta, Departamento de Proyectos Arquitectónicos, Universidad Europea

\section{Francisco Javier Montero}

Dr. Arquitecto, Departamento de Proyectos Arquitectónicos, ETSA-US

\section{Antonio Peña Cerdán}

Arquitecto, Departamento de Proyectos Arquitectónicos, ETSA-UPV

\section{Ana Portalés Mañanós}

Dra. Arquitecta, Departamento de Urbanismo, ETSA-UPV

\section{Amadeo Ramos Carranza}

Dr. Arquitecto, Departamento de Proyectos Arquitectónicos, ETSA-US

\section{Jaume Roset Calzada}

Dr. Físico, Departamento de Física Aplicada, ETSAB-UPC

José Vela Castillo

Dr. Arquitecto, IE School of Architecture and Design, IE University (Segovia, Spain) 


\title{
La fotografía en el aprendizaje, ideación y comunicación de la arquitectura
}

\section{Photography in learning, ideation and communication of architecture}

López-Rivera, Javier

Departamento de Expresión Gráfica Arquitectónica, ETS Arquitectura.Universidad de Sevilla Irivera@us.es

\begin{abstract}
The images no longer represent the world: they are part of it, they are incorporated into it. Photography no longer serves to document the world, even deprived -by the prior digital image- of sufficient validity to document constructed architectures. "Photography has stopped serving as a document of reality to become a carrier of ideas." In the face of this panorama, we ask ourselves What should be the presence and the role that photography must play within the schools of architecture and in the integral formation of the future architect?. The teaching experiences reported in this text show us the relevance of using photography as a tool for graphic communication of architectural ideas, with a high degree of expressiveness and a great capacity to promote sensitivity and creativity in the student.
\end{abstract}

Keywords: photography, architecture, ideas, communication, analysis, expression.

\begin{abstract}
Resumen
Las imágenes ya no representan al mundo: forman parte de él, se incorporan a él. La fotografía ya no sirve para documentar el mundo, despojada incluso -por la imagen digital previa- de la validez suficiente para documentar arquitecturas construídas. "La fotografía ha dejado de servir como documento de la realidad para pasar a ser portadora de las ideas". (Fontcuberta, 1997) Ante este panorama, nos preguntamos ¿Cuál debe ser la presencia y el papel que debe jugar la fotografía en el seno de las escuelas de arquitectura y en la formación integral del futuro arquitecto?. Las experiencias docentes relatadas en este texto nos revelan la pertinencia de utilizar la fotografía como herramienta de comunicación gráfica de las ideas arquitectónicas, dotada de un alto grado de expresividad y de una gran capacidad para fomentar la sensibilidad y creatividad en el alumno. ${ }^{1}$
\end{abstract}

Palabras clave: fotografía, arquitectura, ideas, comunicación, análisis, expresión.

Bloque temático: 4. Antecedentes del aprendizaje en Arquitectura

\footnotetext{
1 "Aparte de la escritura en prosa, no hay otro arte que abarque tanto y ofrezca posibilidades expresivas tan variadas como la fotografía". Antonio Muñoz Molina.
} 


\section{Introducción: un mundo visual}

Habitamos en un mundo plagado de imágenes. Vivimos, sin duda, en una cultura con predominio de lo visual. Las imágenes ya no representan al mundo: forman parte de él, se incorporan a él. "Adios a las imágenes del mundo. Bienvenidos al mundo de las imágenes" (Fontcuberta, 1997). Si hiciésemos un cálculo del número de imágenes que manejamos al cabo del día, nos llevaríamos una gran sorpresa y, en este aspecto, las generaciones de estudiantes superan con creces a las más maduras, donde solemos ubicarnos los docentes.

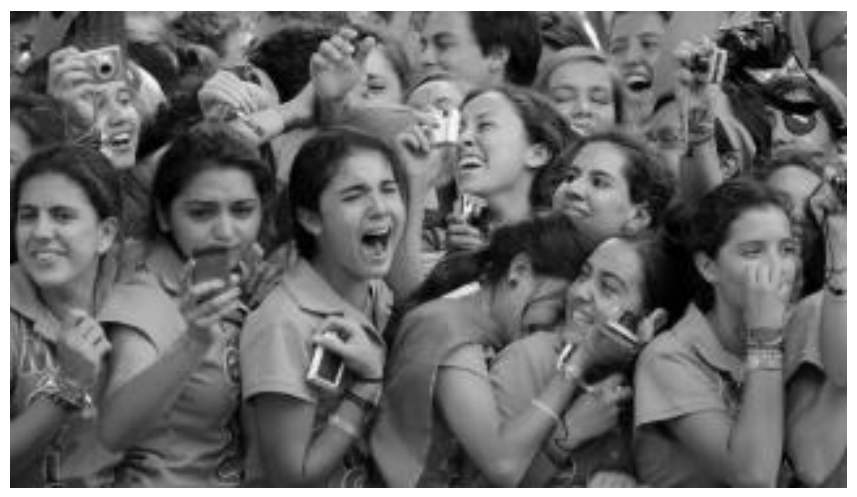

Fig. 1. Pedro Armestre. Jóvenes en la visita del Papa a Madrid. 2011. Fuente: Diario El Pais

Si convenimos que el arquitecto debe comprender el mundo que le rodea para -solo así- ser capaz de intervenir sabiamente en él, llegaremos a la convicción de que es necesario que sepa conocer y manejar con soltura las claves del lenguaje visual que nos rodea. La arquitectura debe expresarse fundamentalmente de forma gráfica. "Si consideramos la fotografía como un medio de expresión, es decir, un lenguaje, significa que podemos escribir con él. Expresarse con la cámara significa comunicarse. El problema es que no nos han enseñado todavía a leer ni a escribir con él. Es un lenguaje diferente que necesita que nos pongamos todos a aprender, porque las posibilidades son inmensas" (Marina, 2014).

Por otro lado, la fotografía ya no sirve para documentar el mundo, como ocurría en los albores de la disciplina, a mitad del siglo XIX. Tampoco posee -apenas ya, en los inicios del XXI- la validez suficiente para documentar arquitecturas construídas recién finalizadas, pues antes de que éstas hayan iniciado su proceso constructivo, ya nos ha sido posible visualizar su final, de forma hiperrealista, gracias a las imágenes digitales previas, dotadas de un halo de perfección ideal. Frente a este panorama, la pregunta que nos hacemos y a la que tratará de responder el texto de esta comunicación es:

¿Cuál debe ser la presencia y el papel que debe jugar la fotografía en el seno de las escuelas de arquitectura y en la formación integral del futuro arquitecto?.

\section{Fotografía como lenguaje, medio y herramienta de expresión gráfica}

Existe un eterno debate en el seno de una gran parte de los departamentos de expresión gráfica (DEGA) -a veces dormido, pero nunca eliminado del todo-, sobre la validez de la utilización de determinadas 'herramientas gráficas' en la expresión de la arquitectura. A principios de los noventa, con la irrupción de los programas informáticos de dibujo asistido por ordenador, se suscitó una amplia polémica acerca de la validez de esas nuevas herramientas sobre las ya tradicionales como el grafito y, sobre todo, acerca de la necesidad de incluir su 
aprendizaje en la programación docente reglada de la ETSA. Algo parecido comienza a suscitarse en nuestros días con la aparición del sistema BIM.

La presencia de la fotografía en determinados espacios de las asignaturas regladas, y con más intensidad en las no regladas, no hace sino contribuir al eterno debate que, por otra parte, no hace sino centrar la polémica en los medios o herramientas utilizadas, sin entrar a fondo en el grado de consecución de los objetivos planteados. Este debería ser, a mi juicio, el tema principal de discusión. No hay herramienta mala en si misma; unicamente en ocasiones será inadecuada en función de los objetivos buscados, que siempre deben ir por delante de la elección de una u otra herramienta. El alumno siempre ha de hacerse primero preguntas encabezadas por un Qué, antes de las que comiencen por un Cómo.

Sirva como ejemplo el caso de una vulgar caja de herramientas, donde el destornillador no es peor que el alicate, ni éste mas desaconsejado que el martillo. Todo dependerá de lo que necesitemos en cada momento y todas ellas serán oportunas cuando la ocasión lo requiera. De igual manera podíamos relatar para el caso de un garaje donde se guarden vehículos de muy distinta gama. En si mismo, no es peor el todoterreno que el descapotable, ni éste es más desfavorable que el familar ranchera. La cuestión será elegir el adecuado para cada acto. A pocos se le ocurriría, al acudir a una boda de postín, elegir el todoterreno lleno de barro en vez del impecable deportivo.

Modestamente, creo que la universidad no debe ser el foro donde se aprenda el manejo, el dominio o la técnica de ninguna herramienta, por novedosa, atractiva y útil que parezca. Para ello ya hay múltiples opciones privadas fuera de la universidad. En las aulas debemos enseñar las claves de cada herramienta, sus virtudes y defectos, asi como la mejor manera de aplicarlas al hecho arquitectónico.

Los aparición de los nuevos planes de estudios 2010-2012 de la ETSA de Sevilla, supusieron la reforma de todas asignaturas del DEGA. Y así, de forma muy esquemática, podríamos resumir que en D1 de trabaja sobre habilitación gráfica; en D2 se trata acerca de la expresión y comunicación de la arquitectura y en D3 sobre el análisis grafico de la misma. La nueva asignatura (D4, ideación y configuración) incide sobre la representación, expresión y comunicación grafica de la idea arquitectónica. $Y$ es en el seno de dicha asignatura donde creo debe jugar un papel importante la fotografía -y en general las imágenes- en la formación reglada del futuro arquitecto, principalmente como una herramienta válida para expresar las ideas arquitectónicas. En ocasiones es difícil de superar la capacidad de síntesis que una sóla fotografía aporta como vehículo de transmisión de la idea central del proyecto.

El fotógrafo plasma sus ideas en forma de fotografías y el arquitecto las suyas en forma de arquitecturas. Hay que distinguir claramente idea de forma. Las ideas no tienen forma, y una misma idea puede concretarse en muy diversas formalizaciones. Imaginar es producir imágenes mentales. La mente piensa con imágenes para, posteriormente, producir otras imágenes. 


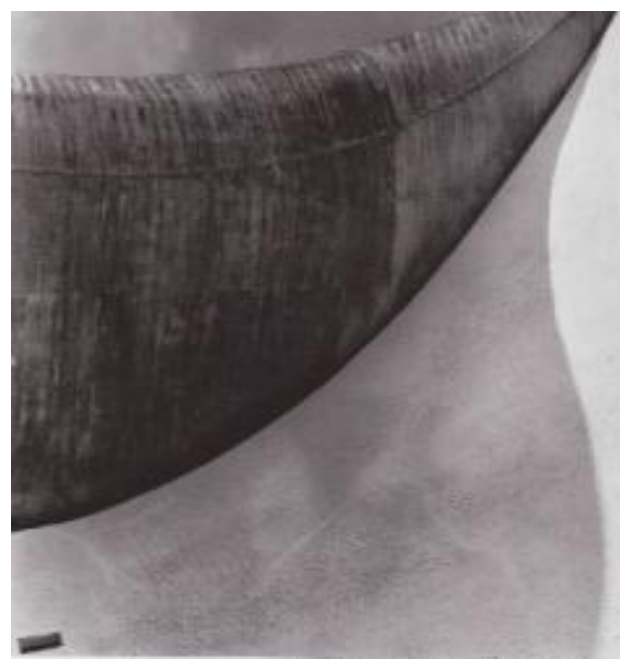

Fig. 2. Lucien Hervé. Ronchamp. 1953. Fuente: BEER, O.(2001). Lucien Hervé. l'homme construit. Paris : Editions du Seuil.

Es el pensamiento visual, que debe caminar de la mano del lenguaje visual, no exento de claves propias que interesa que el futuro arquitecto conozca. No existen, por ejemplo, imágenes inocentes. En muchas ocasiones tan importante es lo que aparece como lo que se deja fuera, lo que se muestra como lo que se oculta, todo lo cual implica una contínua toma de decisiones, muy similar al quehacer arquitectónico.

\section{Estrategias arquitectónicas a través del medio fotográfico}

"El dibujo moderno de arquitectura es interesante, la fotografía es magnífica, el edificio es un desafortunado pero necesario estado entre los dos". ${ }^{2}$

Esta comunicación se enmarca en el campo de la investigación que se ocupa de la multiplicidad y la complejidad de la expresión y la comunicación de la idea y la producción arquitectónica. Y, más en concreto, de las relaciones entre la arquitectura y otras artes visuales frecuentemente denominadas fronterizas o tangenciales, como es el caso de la fotografía. Y es que "la arquitectura moderna quizás sólo se pueda entender en su totalidad cuando se estudia conjuntamente con la fotografía, el cine, la publicidad, u otras formas de expresión visual." (Colomina, 2010)

Muchas son las diferencias entre estas dos artes, y quizás sea ahí donde radique mi interés sobre estas cuestiones: la arquitectura es una disciplina muy antigua (la fotografía es reciente: desde 1827); los procesos de la arquitectura son muy lentos, cada vez más (la fotografía es, ahora más que nunca, instantánea); ${ }^{3}$ la arquitectura es pesada, frente a la ligereza de la fotografía; la fotografía se transporta, algo imposible para algunas arquitecturas; y por último, la fotografía se acumula y almacena, algo difícil de hacer con la arquitectura.

La fotografía nos remite a un espacio físico muy concreto, a veces irreconocible. Asimismo, y frente al mundo acelerado que nos contempla, la fotografía nos permite detener el tiempo,

\footnotetext{
2 H.S. Googhart-Rendel, 1930.

${ }^{3}$ Sobre la lentitud en los procesos de la arquitectura, Giorgio Grassi ya advertía de esta manera, en una conferencia en la Escuela de Arquitectura de Florencia en 1989: "A mi juicio, el aprendizaje es un proceso muy largo, muy largo y muy dilatado; en realidad pienso en un tiempo mucho más largo, pienso que el nuestro es un oficio conveniente a los longevos."
} 
apresarlo, condensarlo en un instante. El fotógrafo trabaja siempre en el presente, no puede recurrir al pasado, ni tan siquiera como argumento. La fotografía tiene la virtud de citar a quien la ve en ese lugar donde nunca antes estuvo. Esto mismo ocurre con la emoción: la que sentimos como espectadores frente a la percibida por el artista al disparar. Precisamente estos tres conceptos, espacio, tiempo y emoción, están indisolublemente asociados a la arquitectura. $^{4}$

Susan Sontag establece en su obra Sobre la fotografía varios paralelismos entre las dos disciplinas y describe a la arquitectura como el arte que más se asemeja a la fotografía, al afirmar que las obras construídas están sometidas a la misma e inexorable promoción con el paso del tiempo que las fotografías. "A fotógrafos y a arquitectos nos une una actividad que requiere una definición precisa de los límites de la mirada, el interés por el encuadre". 5

Pero sobre todo existen múltiples similitudes entre el proyecto fotográfico y el proyecto arquitectónico. En ambos casos, lo primero que han de hacer fotógrafo y arquitecto es hacerse preguntas, múltiples preguntas, antes de disparar, antes de dibujar. (Qué quiero contar?, Cómo lo voy a contar? De qué forma lo voy a presentar?, etc.). Dos citas nos lo recuerdan: "La mirada se hace inteligente -y por tanto creadora- cuando se convierte en una búsqueda dirigida por un proyecto" (Marina, 2006). "La fotografía es una acción inmediata, el dibujo una meditación. Hay que pensar antes y después. Jamás cuando se hace la fotografía". ${ }^{6}$

Gabriel Brau, fotógrafo y docente, estructura el índice de su libro titulado Visión fotográfica y lenguaje visual en tres grandes apartados, referidos a la fotografía: Pensar, Construir e Interpretar. Rafael Moneo, arquitecto y docente, tituló Idear, Representar, Construir, la conferencia inaugural del Congreso EGA celebrado en Sevilla en 2006. Dos triadas de verbosacciones cuyas similitudes saltan a la vista y que refuerzan la tesis que defiendo en este apartado de la comunicación.

A caballo entre la fotografía y la construcción, la obra de Chema Madoz ejemplifica parte de lo relatado. El artista es capaz de ver la obra acabada en su mente, antes de comenzar a construirla, para luego fotografiarla. "La visión es, en realidad, una construcción" (Brau, 2017). Todas sus obras transmiten una idea, un concepto, un mensaje claro: tal como debería ser la buena arquitectura, aquella que, como dijo De la Sota, es capaz de "dar libre por gato". En el fondo, fotografiar es encontrar algo interesante en un lugar ordinario, allí donde el común de los mortales no vería nada.

\footnotetext{
4 Espacio, tiempo y arquitectura fue, precisamente, el titulo del libro con el que el historiador suizo Sigfried Giedion compiló por vez primera en 1941 una historia canónica de la arquitectura y el urbanismo modernos, desde el Renacimiento hasta los años 60 . ). El legado fotográfico de Giedion, que incluye el centenar de fotografías que tomó en España durante su viaje de 1932 con motivo de la reunión preparatoria de Barcelona, se encuentra en el GTA Archiv del Institut für Geschichte und Theorie der Architektur, ETH Zurich.

5 Juan Luis Trillo de Leyva, catedrático de proyectos de la ETSAS, en el prólogo de (López, 2011), titulado Reflexiones de un observador.

${ }^{6}$ Henry Cartier-Bresson. Fotógrafo francés
} 


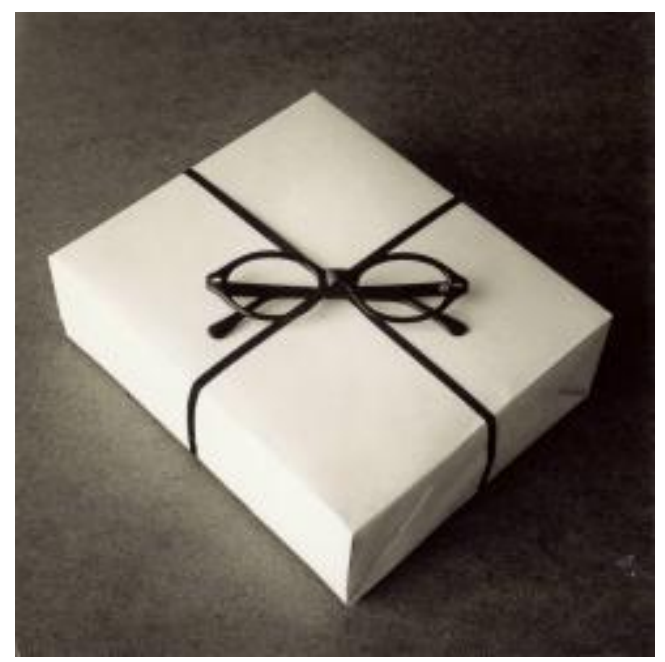

Fig. 3. Chema Madoz. s/t. Fuente: MADOZ, Ch.; BROSSA, J.(2010). Fotopoemario. Madrid: La Fábrica.

Los procesos de descarte (decisión y selección) que guían el trabajo del fotógrafo encuentran similitudes en las labores iniciales del proyecto, donde el arquitecto ha de ir explorando opciones, cerrando una serie de caminos y escogiendo a la vez otros. Se trata, pues, de educar la capacidad critica del alumno para distinguir -ante el apabullante número de imágenes que manejamos a diario-, calidad frente a cantidad. "El fotógrafo, para explicar algo, ha de saber escoger y realizar la fotografía de la manera que más claramente muestre lo que quiere comunicar. Después, se ha de establecer un orden y, sobre todo, no se ha de pretender decir mucho, sino poco y bien dicho." 7

En nuestros días, los arquitectos se tornan fotógrafos (la cámara sustituye al croquis), mientras que los fotógrafos se hacen en cierto modo arquitectos (la lente es una herramienta más del arquitecto). "La cámara fotográfica es un mínimo espacio arquitectónico que confina la oscuridad, un objeto pasivo que aguarda mientras el objetibo enfoca una determinada imagen [...] Es estimulante comparar el marco arquitectónico con el encuadre fotográfico, en cuanto a que ambos operan sobre la realidad y su transformación." 8

El alumno debe, asimismo, conocer los recursos del lenguaje visual y aplicarlos a la expresión y comunicación gráfica de sus arquitecturas. "No es la palabra el medio de expresión del arquitecto", ya lo dijo De La Sota. Uno de los primeros ejemplos -inacabado en 1929 a la muerte de su autor- de construir un discurso con predominio de la imagen frente a la palabra es el Atlas Mnemosyne de Aby Warburg, basado en las relaciones y correspondencias obtenidas al juntar determinadas imágenes, aparentemente inconexas, y donde la fotografía constituye el único medio de expresión de la idea artística (Warburg, 2010).

Como veremos en el próximo apartado, de trata de aprender a construir una verdadera narración gráfica que sea capaz de transmitir la idea de nuestra arquitectura, exclusivamente con imágenes. El alumno deberá trabajar con aspectos básicos que forman parte de la estrategia compositiva de cualquier fotolibro: orden, posición, tamaño, agrupación, secuencia, ritmo, silencios, pausas, etc. En definitiva, variables y acciones puramente arquitectónicas. "El fotógrafo ha de "ver" la Arquitectura, digerirla, interpretarla y expresarla en

\footnotetext{
${ }^{7}$ Francesc Catalá-Roca. Fotógrafo

${ }^{8}$ Juan Luis Trillo de Leyva en el prólogo de (López, 2011), titulado Reflexiones de un observador.
} 
una serie de fotografías, que debido a su orden escrupulosamente escogido, hacen que ni sobre ni falte ninguna." ${ }^{9}$

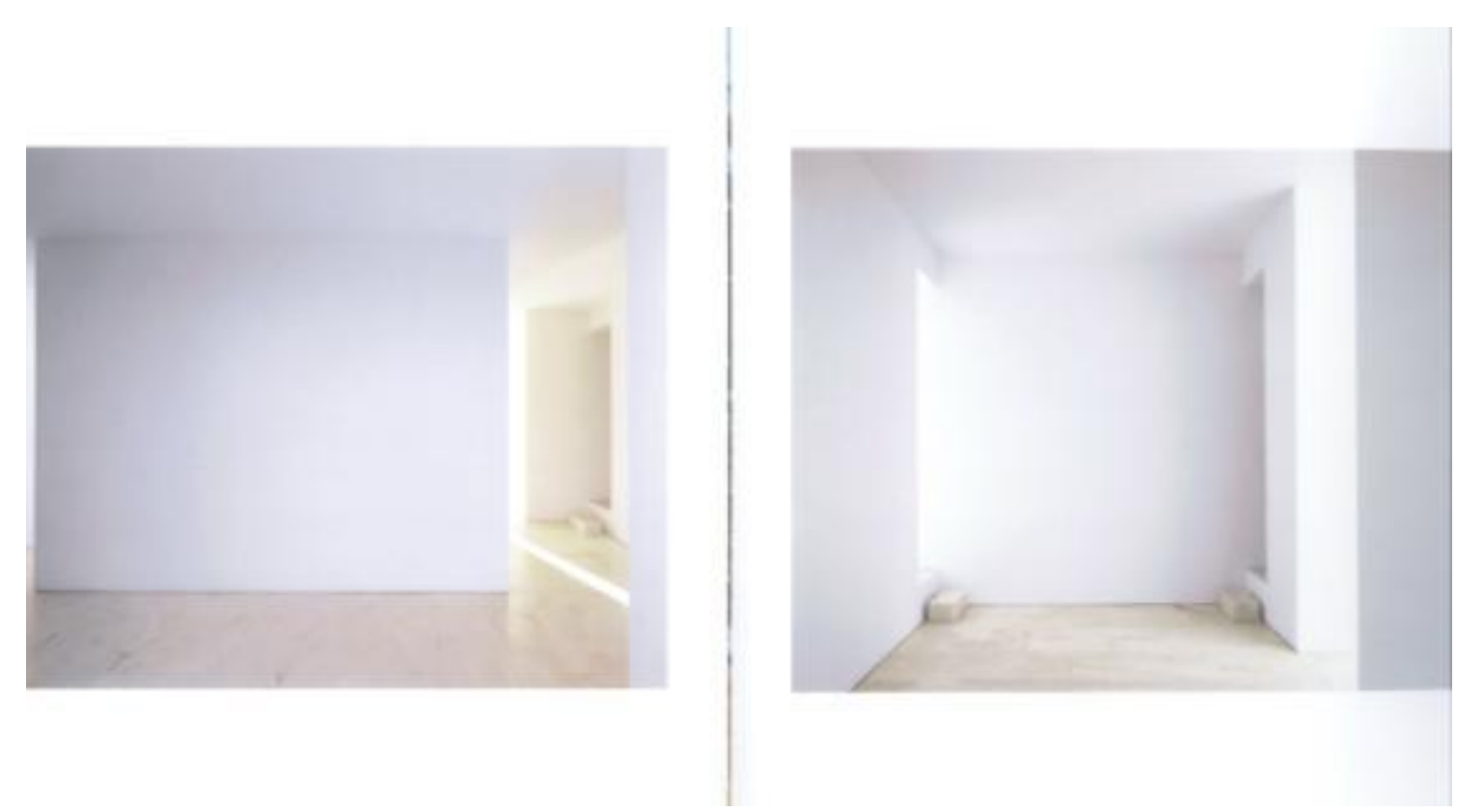

Fig. 4. Daniel Malhao.Casa en Melides. Fuente: AA. VV.(2005). Aires Mateus. Lisboa: Almedina y CC Belém.

\section{Experiencias docentes}

Recuerdo, de forma imborrable, como una de las experiencias docentes más gratificantes, la recibida como alumno de la ETSAS en la asignatura de proyectos por el profesor Manuel Trillo, fallecido un día de primavera de 2005. A la vuelta de un viaje de estudios realizado a Marruecos en diciembre de 1988, la propuesta consistía en recoger, por parte del profesor y sin previo aviso, los carretes de diapositivas, ya revelados, que todos los alumnos y profesores asistentes habían realizado durante un productivo viaje a las esencias del Magreb. El catedrático efectuaba entonces una selección de aquellos que a su juicio parecían más interesantes, con los que se efectuaba posteriormente una proyección y comentarios públicos en el aula.

Allí pudimos sorprendernos al observar con claridad la amplia diversidad de miradas, intereses, puntos de vista y encuadres que, sobre los mismos temas y lugares que todos habíamos visto y recorrido, podían producirse en un ámbito reducido de personas que además estaban recibiendo la misma formación. "No siempre unos ojos bonitos saben mirar. Los ojos los da la naturaleza, la mirada es cultural". ${ }^{10}$ Con ello trató de explicarnos cómo debería ser la mirada de un arquitecto, una mirada selectiva; cómo educarla, como acostumbrarla y cómo marcar la diferencia con la de un alumno formado en otras disciplinas. Por suerte, fuí uno de los seleccionados y creo que desde entonces le debo mi interés por estas cuestiones.

\footnotetext{
9 Pedro Pegenaute. Fotógrafo

10 Frase pronunciada por Francisco Jarauta, presidente del tribunal constituído con motivo de la lectura de la tesis del doctorando D. Ramón Pico Valimaña, titulada Mil pies. Arquitectura y Aviación: de la fascinación por la máquina a la experiencia de la altura, leída en la ETSA de Sevilla el 14/12/2001.
} 
Otras experiencia docente relativa a estos términos, y que considero oportuno referir, es la relatada por Eva Serrats, artista catalana que trabaja paralelamente las disciplinas del cine, la fotografía y la arquitectura. Fue realizada en un taller semanal de fotografía de un máster de arquitectura en Barcelona y su finalidad era la de expresar y contar cosas sobre el lugar elegido para un proyecto urbano, sin emplear las palabras, con un número cada vez más reducido de imágenes, de forma muy concreta y personal. Las primeras cuestiones suscitadas a los alumnos versaban sobre qué cuentan mis imágenes y qué aspiran a contar, y por tanto sobre la búsqueda de estrategias para mejorarlas y conseguir ese objetivo. Supone un claro ejemplo de ejercicio de descarte, pues de una primera exposición pública en el aula sin límite, se pasó a una selección de diez fotos que, paulatinamente fue descendiendo a tres, y luego a dos, para, finalmente, ser capaces de resumir en una sola imagen todo el proceso de conocimiento y opinión sobre el lugar, concreto y personal. ${ }^{11}$

En mi caso personal, llevo varios años trabajando estos temas en asignaturas regladas y no regladas en la ETSA de Sevilla. En el caso de la docencia reglada, introduciendo en el programa docente de la asignatura de tercer curso D4 -ideación y configuración- un breve ejercicio de tres semanas sobre fotografía. No se trata, en este caso, de que el alumno use su cámara fotográfica, sino de que analice y maneje "disparos" realizados por otros.

El ejercicio pretende indagar sobre las relaciones entre las dos artes, sus conflictos, los procesos de construcción de la mirada analítica y sus medios de difusión y consumo, así como sobre el papel que la fotografía desempeña como herramienta válida en el proceso de proyecto, a la luz de algunos ejemplos de autores contemporáneos. Cada vez son más numerosos los momentos en los que la fotografía aparece en el desarrollo de un proyecto, no sólo para documentar su estado final.

Se propone el caso de dos estudios de arquitectura, coincidentes en el tiempo y en las circunstancias históricas en las que se desarrollan: Alison \& Peter Smithson y Le Corbusier. Ambos concedieron -de forma muy diversa- una gran importancia a la fotografía como complemento de su labor proyectual: Como transmisora de referentes, como portadora de las claves del lugar, como registro y chequeo espacial de resultados futuros, o como reflejo de las ideas finalmente construídas. Se analizan en clase las intensas y a veces traumáticas relaciones profesionales mantenidas con determinados fotógrafos, según los casos: Nigel Henderson o Sandra Lousada en el caso de Los Smithson; y Lucien Hervé -entre otros muchos- en el caso de Le Corbusier. Asimismo, el alumno ha de indagar sobre la labor fotográfíca personal de Peter Smithson y del maestro suizo, recientemente sacada a la luz en los magnificos trabajos de Tim Benton (Benton 2013).

Con los conocimientos adquiridos en estos análisis, el alumno ha de elaborar un discurso personal, una verdadera narración exclusivamente gráfica -es decir, un fotolibro- sobre las relaciones existentes entre fotografía e idea arquitectónica en el caso de los autores seleccionados, muy diferentes por otra parte. Por último, el alumno elegirá una sóla fotografía, de entre todas las manejadas en su análisis y escribirá sobre ella un breve texto (máx. 400 palabras o 2500 caracteres) que la acompañe. Buscamos textos evocadores -no descriptivosque pongan en valor el papel de la mirada fotográfica y que destilen una enriquecedora enseñanza arquitectónica.

\footnotetext{
${ }^{11}$ Fotografía como herramienta de proyecto, en (Serrats, 2011).
} 

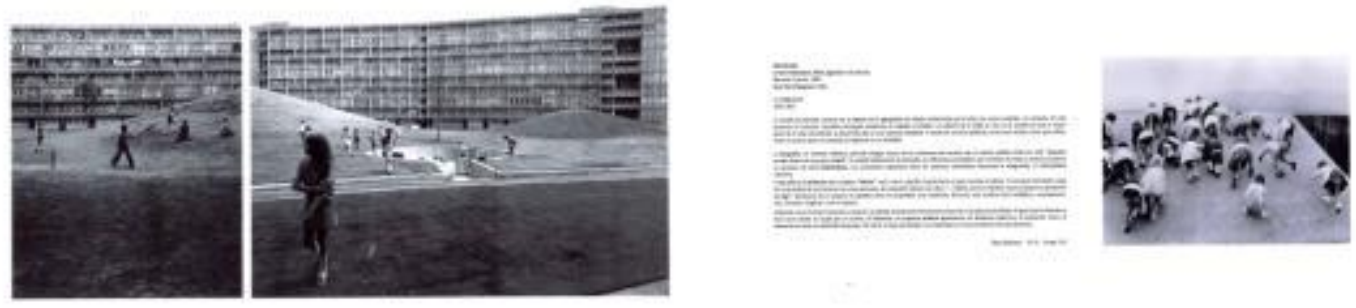

Fig. 5. Trabajos de curso. D4 2016-17. Abraham Sánchez y Olaya Baktaoui. Fuente: DEGA, ETSA, Sevilla.

El resultado de este estudio, así como la fotografía-texto final se compilan en un máximo de 5 formatos A3. Como ya ha sido apuntado con anterioridad, el alumno deberá trabajar con aspectos básicos que forman parte de la estrategia compositiva de cualquier fotolibro: orden, posición, tamaño, agrupación, secuencia, ritmo, silencios, pausas, etc. Las opciones son variadas, si bien no caprichosas, desde dedicar dos formatos por autor -alternandolos 0 poniéndolos a continuación-, hasta establecer comparativas entre ambas formas de relación dentro de cada formato, pasando por comparativas formato a formato. La elección de una única foto final, que resuma todo lo trabajado, trata de entrenar al alumno en los procesos de descarte fotográficos, tan parejos con los de destilación de la idea arquitectónica, aun sabiendo que, para algunos autores como Richard Neutra, una imagen nunca puede contarlo todo, pues "es sorprendente lo difícil que resulta capturar la esencia de un edificio" (García, 2015).

En cuanto a la docencia no reglada, dos han sido las experiencias realizadas y una tercera se prevee para este nuevo curso. En todas ellas, se trata de cursos regulados por el Centro de Formación Permanente de la Universidad de Sevilla, de diferente carácter y extensión. Y así, en el curso 2015-16, dirigí la primera edición del curso de extensión universitaria denominado Visiones Arquitectónicas de la Fotografía, realizado en diez sesiones semanales de 3,5 horas ( 3,5 créditos), que camina ya por la III Edición. De este embrión, surge el pasado año el curso de formación contínua denominado Fundamentos de Fotografía y Arquitectura, realizado en colaboración con un grupo de profesores de la ETSA de Málaga, de 16 sesiónes semanales de 4-5 horas, con un total de 7 créditos, que duplicaba en extensión al anterior.

Para este curso 2017-18 está prevista la I Edición del curso de experto en Fotografía y Arquitectura en colaboración con el mismo grupo de profesores de la ETSA Málaga, que de nuevo, duplica en extensión al anterior (15 créditos, 16 sesiones de 5 horas), ampliando principalmente los contenidos prácticos y de taller fotográfico, e incorporando a profesionales de la talla de Rafael Doctor, Marina-Morón, Jesus Granada, Manolo Laguillo o Jorge Yeregui. En todos los casos, el número de alumnos ha oscilado entre 10 y 15 , lo que posibilita, en general, la calidad de la docencia, la cercanía a los maestros y una tutorización personalizada. La procedencia de los alumnos es variada: desde alumnos de grado en Arquitectura, hasta Arquitectos jóvenes en ejercicio profesional, pasando por Aparejadores titulados. 


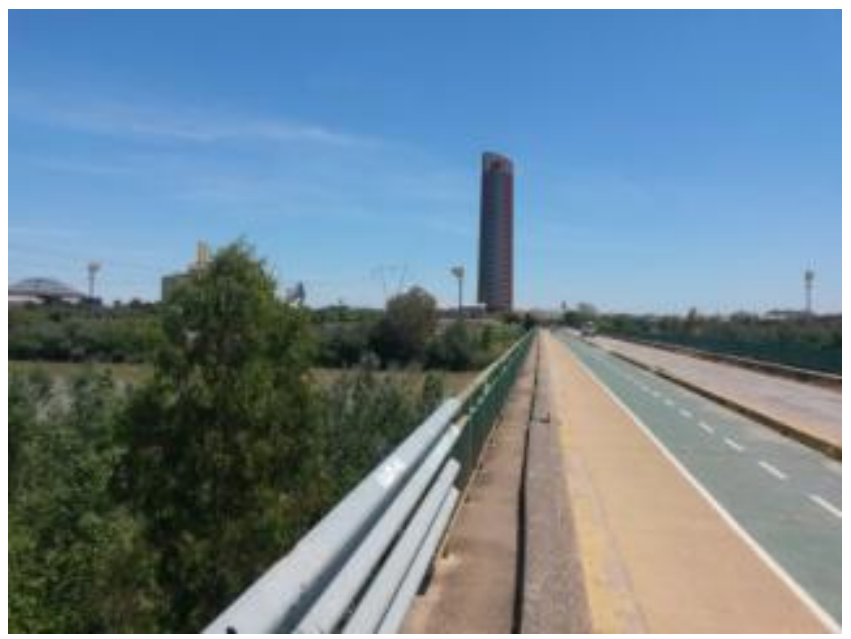

Fig. 6. Jorge Yeregui.Sevilla. Fuente: Taller de Paisaje. Curso Fundamentos de Fotografía y Arquitectura.

En cuanto a los objetivos generales perseguidos por este hilo argumental de cursos sucesivos, que van creciendo en extensión y contenidos, y que tienen como objetivo final a medio plazo la consecución de un máster andaluz en fotografía de arquitectura, podríamos resumirlos de la siguiente manera:

- No se trata de transmitir enseñanzas técnicas avanzadas sobre el manejo de la cámara fotográfica, pues consideramos que la enseñanza universitaria no debe servir para eso, siendo, por el contrario, abundante la oferta privada en la calle en esta materia.

- Desarrollar un corpus teórico de conocimiento en el que convergen ambas materias, fomentando la multidisciplinariedad como forma de aprendizaje especializada para la formación de expertos.

- Dotar al alumno de conocimientos teóricos sobre la relación histórica entre fotografía y arquitectura, sobre las obras y los grandes autores de fotografía de arquitectura, y sobre la construcción de la imagen de la arquitectura moderna a través de la fotografía.

- Iniciarles en las teorías de la composición y el diseño aplicados a la presentación del trabajo fotográfico como herramienta de narración, comunicación y representación de las ideas.

- Dotar al alumno de los conocimientos y técnicas necesarios para realizar todo el proceso desde la planificación del proyecto fotográfico, la toma fotográfica, la presentación y entrega, pasando por el flujo de trabajo en la postproducción digital y la edición, e incluso la exposición final del trabajo. Incidir en la concepción del proyecto fotográfico como un proceso integral que no se limita al instante de la toma de la imagen y al retoque en postproducción sino que comprende además una fase previa de organización y preparación del proyecto.

- Potenciar la capacidad creativa del alumno para expresar con la fotografía ideas, narraciones, análisis, de la arquitectura a través de la experimentación en los ejercicios prácticos, de las experiencias transmitidas por docentes y profesionales en las ponencias y del análisis de ejemplos de reconocidos autores en las sesiones teóricas.

- Desarrollar la capacidad crítica del alumno para valorar las imágenes por su calidad, frente a la cantidad que ofrecen a diario medios y redes sociales.

- Entender la fotografía como vehículo con el que podemos "hablar". Lo que se dice con fotografías no se puede decir de otra manera. Los alumnos adquirirán, mediante la práctica, 
conocimientos técnicos que les familiarizarán con el uso de la cámara, la iluminación natural y artificial o la postproducción, y que les proveerán de un serio conocimiento de cómo "se expresa" la fotografía. Y, por tanto, de cómo puede trascender la mera captura de imágenes y convertirse en un medio de creación.

Todas estas experiencias en docencia no reglada están siendo muy gratificantes y el feed-back recibido de los alumnos no puede ser más positivo, convirtiéndose en el acicate que nos incita a crecer año a año. La corta experiencia nos dice que existe un creciente interés por la materia y que las aulas universitarias deben capitanear este tipo de enseñanzas que, como se ha relatado, van más allá de los meros concimientos técnicos en la materia, proporcionando al alumno profundizar en su educación visual y dotándole de recursos para el empleo del lenguaje visual, ambos necesarios para desenvolverse correctamente en la cultura visual en que estamos todos inmersos.

\section{Bibliografía}

Arquitectura Viva (2013). Modos de ver. № 153. Madrid: Arquitectura Viva S.L.

BENTON, Tim (2013). Le Corbusier. Secret Photographer. Zurich: Lars Müller Publishers

BRAU, G. (2017). Visión fotográfica y lenguaje visual. Madrid: Terra Natio.

COLOMINA, B. (2010). Privacidad y publicidad. La arquitectura moderna como medio de comunicación de masas. Ed. en castellano. Murcia: Colegio de Arquitectos de Murcia.

FONTCUBERTA, J. (1997). El beso de Judas. Fotografía y Verdad. Barcelona: Gustavo Gili.

GARCIA CLARIANA, I. (2015). "Cuestiones de (Re) presentación. Fotografía y álbumes en la arquitectura de Fernando Moreno Barberá" en Fotografía y arquitectura moderna. Contextos, protagonistas y relatos desde España. Barcelona: Fundación Caja de Arquitectos, col. arquia/temas núm. 39.

JARDÍ, E. (2012). Pensar con imágenes. Barcelona: Gustavo Gili.

LÓPEZ, A. (2011). La mirada atenta. Sevilla: IUACC. Universidad de Sevilla.

LÓPEZ-RIVERA, J. (2015). Fotografía y arquitectura modernas. 1925-1939. Andalucía. Margaret Michaelis. Sevilla: Universidad de Sevilla y Junta de Andalucía, col. Kora № 28.

MARINA, José A..(2006). Teoría de la inteligencia creadora. Barcelona: Anagrama.

MARINA, J. (2014). "Mal visto, mal dicho", en Bergera, I., S. Lampreave, R. (Eds.), III Jornada de Arquitectura y Fotografía 2013. Zaragoza: Diputación de Zaragoza y Universidad de Zaragoza.

SERRATS, E. (2011). "Sin tectura ni grafía: arquitectura y fotografía”, en Bergera, I., S. Lampreave, R. (Eds.), I Jornada de Arquitectura y Fotografía 2011. Zaragoza: Institución Fernando el Católico.

SONTAG, S. (1981). Sobre la fotografía. Barcelona: Edhasa

WARBURG, A. (2010). Atlas Mnemosyne. Tres Cantos: Akal.

ZABALBEASCOA, A. (2015). “¿Qué retrata quien fotografía arquitectura?” en Bergera, I., S. Lampreave, R. (Eds.), IV Jornada de Arquitectura y Fotografía 2014. Zaragoza: Diputación de Zaragoza y Universidad de Zaragoza.

ZUMTHOR, P. (2006). Atmósferas, entornos arquitectónicos, las cosas a mi alrededor. Barcelona: Gustavo Gili. 